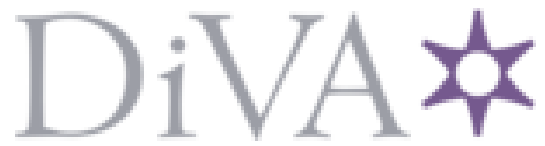

http://www.diva-portal.org

Preprint

This is the submitted version of a paper published in Surface \& Coatings Technology.

Citation for the original published paper (version of record):

Wen, R., Arvizu, M A., Niklasson, G A., Granqvist, C-G. (2016)

Electrochromics for energy efficient buildings: Towards long-term durability and materials rejuvenation

Surface \& Coatings Technology, 290: 135-139

https://doi.org/10.1016/j.surfcoat.2016.02.031

Access to the published version may require subscription.

N.B. When citing this work, cite the original published paper.

Permanent link to this version:

http://urn.kb.se/resolve?urn=urn:nbn:se:uu:diva-297549 


\title{
Electrochromics for Energy Efficient Buildings: Towards Long-Term Durability and Materials Rejuvenation
}

\author{
R.-T. Wen, M.A. Arvizu, G.A. Niklasson, and C.G. Granqvist, \\ Department of Engineering Sciences, The Angström Laboratory, Uppsala University, \\ Uppsala, Sweden \\ *Corresponding author: Ruitao.Wen@angstrom.uu.se \\ Tel: +46-18-471 3144
}

\begin{abstract}
Electrochromic devices such as "smart windows" for energy efficient windows must be durable enough for many years of practical use. Typical devices employ films based on W oxide and Ni oxide, and this paper surveys recent progress on durability-related issues for these materials. In the case of $\mathrm{W}$ oxide, we discuss the beneficial effects of Ti addition, and we describe recent and unexpected progress concerning galvanostatic rejuvenation of aged W oxide films. For Ni oxide, we report how charge exchange declination during extended voltammetric cycling can be modeled in terms of a power law.
\end{abstract}

\section{Introduction}

A large part of the primary energy in the world is spent in buildings. The fraction is as large as $30-40 \%$ on a word-wide scale and the energy is used for heating, cooling, lighting and appliances [1]. Furthermore, the portion that goes into buildings tends to increase, particularly in the more affluent countries, and recent numbers for the US indicate specifically 34, 36, 38 and 41\% for 1980, 1990, 2000 and 2010, respectively [2]. Most of the energy comes from coal, oil and gas and leads to emission of carbon dioxide into the atmosphere, 
which in its turn yields global warming and rising sea level [3] and may even lead to vast secondary effects such as political unrest [4].

The buildings sector is notorious not only for wasting immense amounts of energy but also for its huge savings potential. By and large, these savings are an untapped resource, which is due to poor but thoroughly entrenched building practices [5]. Glazings, denoting windows and glass facades, are particularly important in this connection and often act as weak links in the buildings' energy systems and let through too much thermal and solar energy, so that energy guzzling air conditioning must be used to create a comfortable indoor climate.

The glazings can be very significantly improved by implementing "green" technology and optimize the flows of solar energy and visible light, while the thermal insulation is kept as large as possible [6]. In particular, it is important to regulate the transmittance of solar energy and light through the glazings in accordance with dynamic needs and human desires, which is feasible by use of chromogenic materials whose optical transmittance responds to an external stimulus such as ultraviolet irradiation (photochromic materials), temperature (thermochromics materials), or electrical voltage or current (electrochromic materials, incorporated in electrochromic devices) [7,8]. This paper deals with electrochromic (EC) materials and devices; their state-of-the-art with regard to glazings was summarized recently [9-12]. Below we summarize some recent studies with emphasis on basic work related to long-term durability and materials rejuvenation [13-15], which obviously are important subjects with regard to applications. For detailed descriptions, we refer to the original publications.

\section{Electrochromic device designs and functioning principles}

There are several different types of EC devices [11], but the ones that are presently discussed and implemented as "smart windows" in buildings are of the type illustrated in the right-hand part of Fig. 1 [16-18]. The center of the device consists of a transparent electrolyte, which can be a polymer layer or an oxide thin film, which joins two EC thin films typically based on strongly disordered tungsten oxide and nickel oxide [19]. This three-layer arrangement is located between transparent electrical conductors, which in most cases are heavily doped wide band-gap oxides such as $\mathrm{In}_{2} \mathrm{O}_{3}: \mathrm{Sn}$ (known as ITO), $\mathrm{SnO}_{2}: \mathrm{F}$ or $\mathrm{ZnO}: \mathrm{Al}$ (although many other options exist, including coinage-metal-based ones). When a voltage, typically $\sim 2 \mathrm{~V}$ dc, is applied between the transparent conductors, there is an exchange of ions 
and charge-balancing electrons between the films of $\mathrm{W}$ oxide and $\mathrm{Ni}$ oxide. Both of these films are dark when the charge resides in the $\mathrm{W}$ oxide whereas both of the films are bleached when the charge is in the Ni oxide, which implies that the overall optical transmittance can be varied. The ions in the electrolyte should be small in order to allow facile charge transport and thereby rapid changes of the optical properties, and protons $\left(\mathrm{H}^{+}\right)$or $\mathrm{Li}^{+}$are normally used. We note that EC films of W oxide and Ni oxide are different with regard to their electrochemistry, and ions are able to enter into the lattice structure of $\mathrm{W}$ oxide, whereas electrochemical surface reactions are dominating for $\mathrm{Ni}$ oxide films in $\mathrm{Li}^{+}$-conducting electrolytes [20]. Metallic bus bars on at least parts of the circumference of the EC device are usually needed in order to accomplish charge equilibration and uniform coloration.

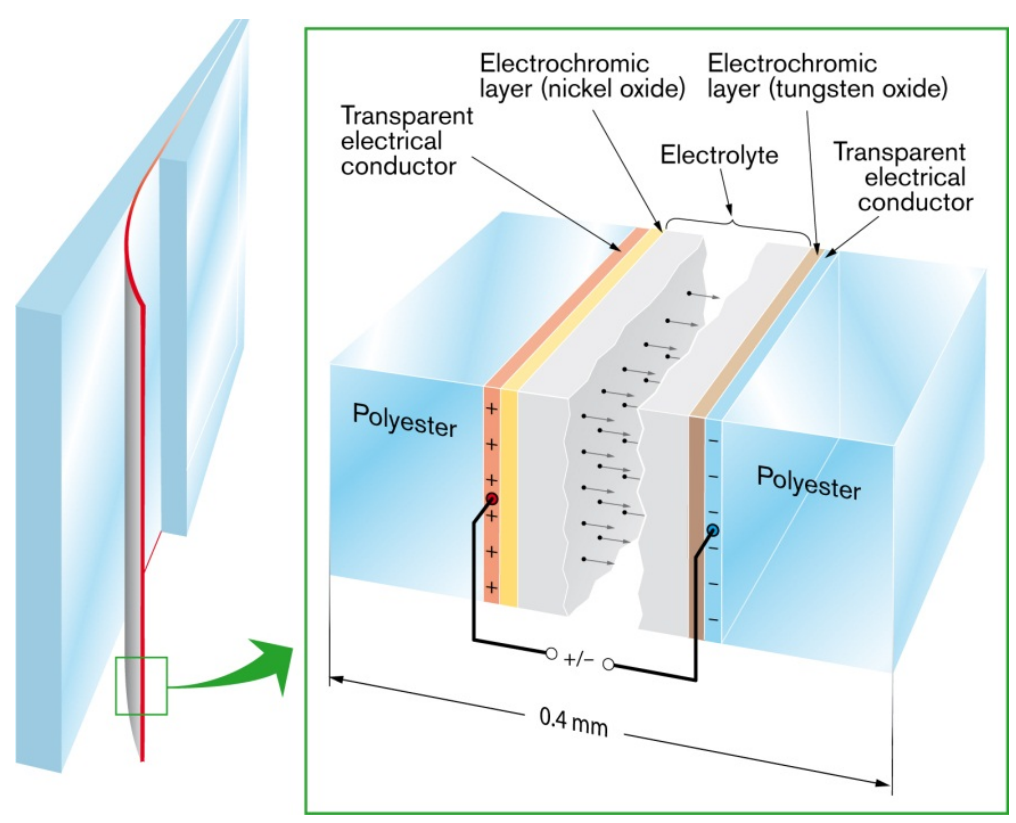

Fig. 1. Principle of a foil-type EC device and its implementation as a laminate between glass panes in "smart windows" for energy efficient buildings. From Bayrak Pehlivan et al. [18].

The functioning of the EC device can be resembled to that of a thin-film battery whose charging state corresponds to a degree of optical absorption. The EC device, just as the battery, can maintain its properties for days or more under open-circuit conditions provided that the centrally positioned electrolyte has low enough electron conduction-which is normally the case for polymer electrolytes but not for inorganic thin-film electrolytes. The fact that charge 
is needed only to alter the properties leads to highly energy-efficient operation of "smart windows”.

The battery-type EC device can be constructed in several principally different ways. Most work has been devoted to a "monolithic" arrangement with five superimposed thin films on a single glass pane. Such a design allows, in principle, large-scale in-line production in the same way as for today's metal-based solar-control and low-emittance coatings [21]. The EC devices produced in this way are delicate and should, for practical reasons, be integrated in EC glazings in conjunction with the coating manufacturing. The need for bus bars necessitates device fabrication in predetermined dimensions. An alternative to the monolithic construction, which was introduced some years ago [22,23] and is illustrated in the left-hand part of Fig. 1, makes the EC device as a flexible two-component foil embodying one foil of polyethylene terephthalate (PET) coated with ITO and W oxide, another foil of PET coated with ITO and $\mathrm{Ni}$ oxide, and lamination by use of a transparent polymer electrolyte joining the films of $\mathrm{W}$ oxide and Ni oxide. This "double foil" can then be used for glass lamination using standard procedures involving polyvinyl butyral (PVB) or ethylene-vinyl acetate (EVA). The foilbased production strategy allows low-cost roll-to-roll deposition [24] and can be combined with "free-form" device manufacturing using post-prepared bus bars. Hence the EC functionality can be separated from the glazing manufacturing, which permits entirely different business models for monolithic and polymer-laminated EC “smart windows”.

\section{W-oxide-based films: General considerations, and improved cycling durability by Ti addition}

Long-term durability is an obvious requirement for EC devices to be used in "smart windows”, and this property has been the subject of numerous studies in particular with regard to device performance and industry aspects; much of this work appeared already in the late 1990s [25-29]. Durability is a multifaceted property and involves the ability to sustain charge transport between the two EC films in a device for many thousand cycles without major changes in the performance, resistance against degradation by solar irradiation for long times, chemical resistance especially at the thin-film/electrolyte interface, sufficient shelf-life, etc.

We first consider $\mathrm{W}$ oxide. This is the material in which electrochromism was discovered [30] and, as far as we know, it is used in all EC devices for glazing applications [11]. The etching of films of this material in acid electrolytes was studied many years ago [31,32] and 
was found to be intolerably high for highly disordered films such as those generally used in EC devices. However, this problem is not believed to be a major one for solid or $\mathrm{Li}^{+}-$ conducting electrolytes. Furthermore, some ultraviolet solar irradiation may be more of a boon than a ban for EC devices and is able to accomplish de-trapping of ions [33], as further discussed in Sec. 4 below, and enhance the optical modulation range [34,35].

Electrochemical cycling durability is a more severe obstacle. However, it was discovered already in the early 1990s that the addition of some Ti had beneficial effects for cycling in $\mathrm{Li}^{+}$-conducting electrolytes [36,37]. Analogous results were found in subsequent investigations [38-42], and recent work has used electrochemical measurements, transmission electron microscopy, atomic force microscopy and Raman spectroscopy to document that $\mathrm{Ti}$ serves as a crystallization impediment so that lattice ordering takes place at an increased temperature when $\mathrm{Ti}$ is present $[39,41]$.

We recently prepared $\mathrm{W}-\mathrm{Ti}$ oxide films with various compositions by reactive dc magnetron sputtering [13]. The films were characterized by Rutherford backscattering spectrometry, X-ray diffraction and atomic force microscopy, and the optical and electrochemical properties were investigated by spectrophotometry and cyclic voltammetry $(\mathrm{CV})$ in a $\mathrm{Li}^{+}$-conducting electrolyte $\left(1 \mathrm{M} \mathrm{LiClO}_{4}\right.$ in propylene carbonate, which was used also in the investigation reported on in Secs. 4 and 5). Figs. 2(a) and 2(b) show cyclic voltammograms for $\mathrm{W}$ oxide films in two ranges: $2.0-4.0 \mathrm{~V}$ and $1.7-4.0 \mathrm{~V}$ vs. $\mathrm{Li}^{+} / \mathrm{Li}$. A gradual decline of the inserted and extracted charge density is apparent, which leads to a concomitant lowering of the optical modulation (optical transmittance was recorded for samples inside an electrolyte-filled cell; data taken with the sample removed were used as a reference). The initial charge exchange, and optical modulation, is largest for the higher voltage sweep range but so is the cycle-dependent degradation of the properties, and clearly most of the electrochromism is lost after $80 \mathrm{CV}$ cycles at $1.7-4.0 \mathrm{~V} \mathrm{vs}$. $\mathrm{Li}^{+} / \mathrm{Li}$. As apparent from Figs. 2(c) and 2(d), this degradation is much less significant in films of $\mathrm{W}_{0.88} \mathrm{Ti}_{0.12} \mathrm{O}_{3}$ and is even smaller for $\mathrm{W}_{0.8} \mathrm{Ti}_{0.2} \mathrm{O}_{3}$. Fig. 3 summarizes data on mid-luminous transmittance for fully bleached and fully colored W-oxide-based films, corresponding to the turning points in the CV data, and demonstrates the ability of the Ti additive to sustain electrochromism up to many cycles. 

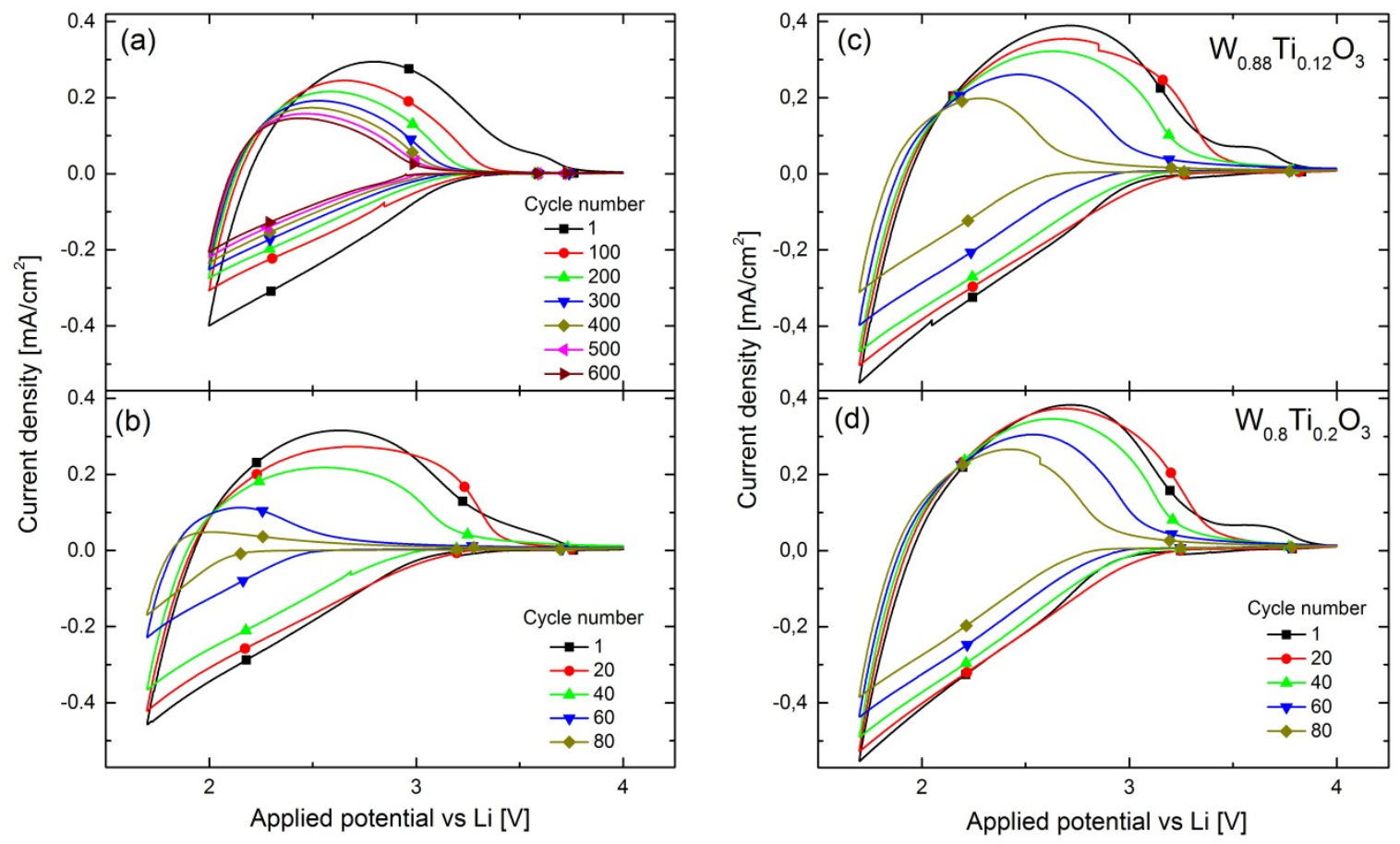

Fig. 2. Cyclic voltammograms for 300-nm-thick films of (a, b) W oxide and (c, d) W-Ti oxide with the shown compositions. Data were taken after the indicated number of CV cycles for voltage sweeps at $10 \mathrm{mV} / \mathrm{s}$ at $2.0-4.0$ or $1.7-4.0 \mathrm{~V}$ vs. $\mathrm{Li}^{+} / \mathrm{Li}$. From Arvizu et al. [13].

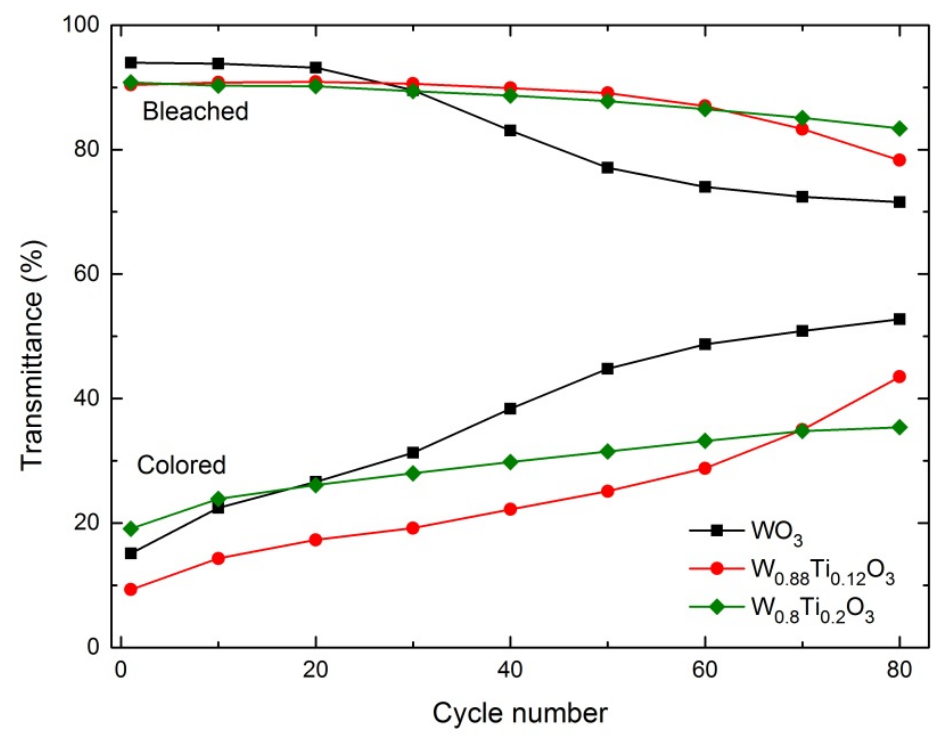

Fig. 3. Evolution of the maximum and minimum optical transmittance at the wavelength $550 \mathrm{~nm}$ for films of W oxide and W-Ti oxide. Data were taken after the indicated number of CV cycles for voltage sweeps at $10 \mathrm{mV} / \mathrm{s}$ at $1.7-4.0 \mathrm{~V} \mathrm{vs}$. $\mathrm{Li}^{+} / \mathrm{Li}$. Symbols denoting data were joined by straight lines for convenience. From Arvizu et al. [13]. 


\section{W-oxide-based films: Galvanostatic rejuvenation}

We recently made the surprising discovery that the cycle-dependent decline of the charge density exchange and optical modulation can be reversed in EC films of $\mathrm{W}$ oxide so that the original properties are recovered [15]. Fig. 4 reports on an experiment, using thin films again made by reactive dc magnetron sputtering and immersed in the same kind of $\mathrm{Li}^{+}$-conducting electrolyte as before, which clearly demonstrates this rejuvenation. Panel (a) shows CV data for a film after the first and $400^{\text {th }}$ cycle in the voltage range $2.0-4.0 \mathrm{~V} \mathrm{vs.} \mathrm{Li}^{+} / \mathrm{Li}$. These data display a clear decrease of the charge density and are similar to those in Fig. 2(a). A corresponding drop of the optical modulation at a mid-luminous wavelength is shown in Fig. 4(c). The open circuit potential (OCP) went from an initial value of $\sim 3.2$ to $\sim 2.8 \mathrm{~V} \mathrm{vs.} \mathrm{Li}^{+} / \mathrm{Li}$ after the $400^{\text {th }}$ cycle.
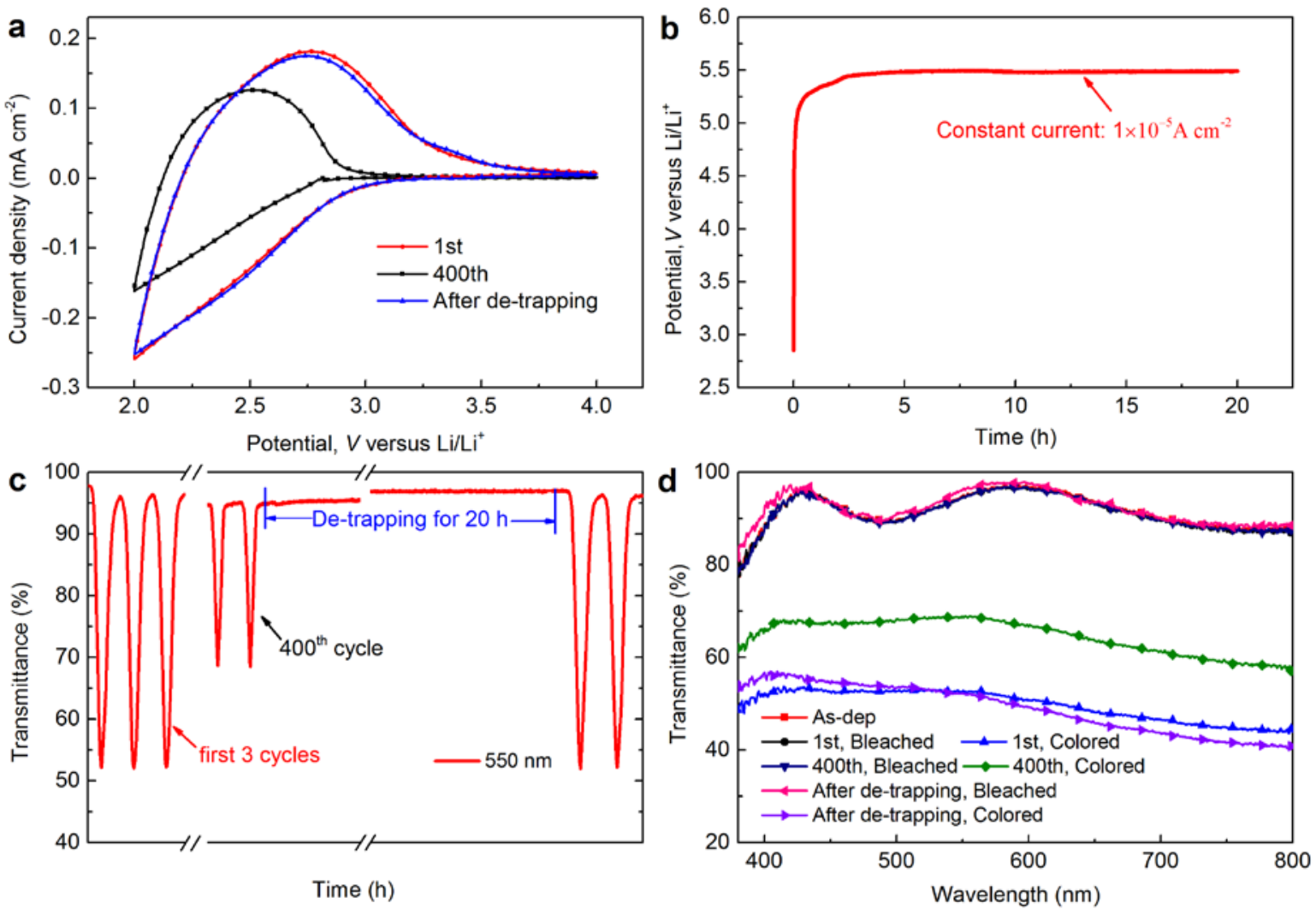

Fig. 4. Galvanostatic rejuvenation of a 270-nm-thick W oxide film, showing cyclic voltammograms recorded at $20 \mathrm{mV} / \mathrm{s}$ (a), voltage upon galvanostatic extraction of trapped ions (b), and optical transmittance at the wavelength $550 \mathrm{~nm}$ (c) and in the full luminous wavelength range (d). Spectral transmittance data are partly overlapping for bleached films. From Wen et al. [15]. 
The device degradation is ascribed to trapping of $\mathrm{Li}^{+}$ions, following notions put forward by Bisquert $[43,44]$. Specifically it was proposed that W oxide films had two types of trapping sites: a network of "shallow" sites allowing reversible and fast diffusion of ions throughout the film, and isolated "deep” traps capable of immobilizing the ions. Subsequent work extended this picture to account for a distribution of trap energies [45,46].

In an attempt to test the trap hypothesis, we applied a constant current density of $10^{-5}$ $\mathrm{Acm}^{-2}$ through the sample for a period of $20 \mathrm{~h}$. It was observed that the potential then rose from $\sim 2.8$ to $\sim 5.5 \mathrm{~V}$ vs. $\mathrm{Li}^{+} / \mathrm{Li}$, as seen in Fig. 4(b), whereas the optical transmittance remained high and almost unchanged. After this galvanostatic loading, the OCP returned to $\sim 3.3 \mathrm{~V}$ vs. $\mathrm{Li}^{+} / \mathrm{Li}$, which indicates that the original properties were regained. Optical data prove that this rejuvenation of the film is indeed at hand, which is apparent from the midluminous data in Fig. 4(c) and also for the spectral optical data in Fig. 4(d) and, furthermore, the original voltammograms were obtained as evidenced by Fig. 4(a). These results hence strongly suggest that de-trapping of $\mathrm{Li}^{+}$ions from “deep” sites is possible, but the practical implications for EC devices need to be investigated in more detail. Strong degradation, consistent with filled “deep” traps, took place if the $\mathrm{Li}^{+}$insertion was excessive. This occurred in practice for $x>0.65$ in $\mathrm{Li}_{x} \mathrm{WO}_{3}$, which is consistent with previous findings [47].

\section{Ni-oxide-based films: Power-law decay of the charge density exchange}

$\mathrm{Ni}$ oxide films immersed in $\mathrm{Li}^{+}$-conducting electrolytes were investigated recently, and it was found that the charge density exchange shrank

upon extended voltammetric cycling, and therefore also the electrochromism, declined steadily [14]. As before, the films were made by reactive dc magnetron sputtering. Fig. 5(a) shows voltammograms for up to 10,000 cycles and Fig. 5(b) reports the charge density exchange $Q$ with a logarithmic scale on the abscissa. The data could be accurately fitted to the strictly empirical expression

$$
Q=A_{2}+\frac{A_{1}-A_{2}}{1+\left(\frac{x}{x_{0}}\right)^{p}}
$$

where $A_{1}$ is the initial charge density and governed by the first CV cycle, $A_{2}$ is a residual charge density observed after a very large number of cycles, $x_{0}$ is the cycle number at which the decline in $Q$ has reached half of its final value and, most significantly, $p$ is a power-law exponent. 

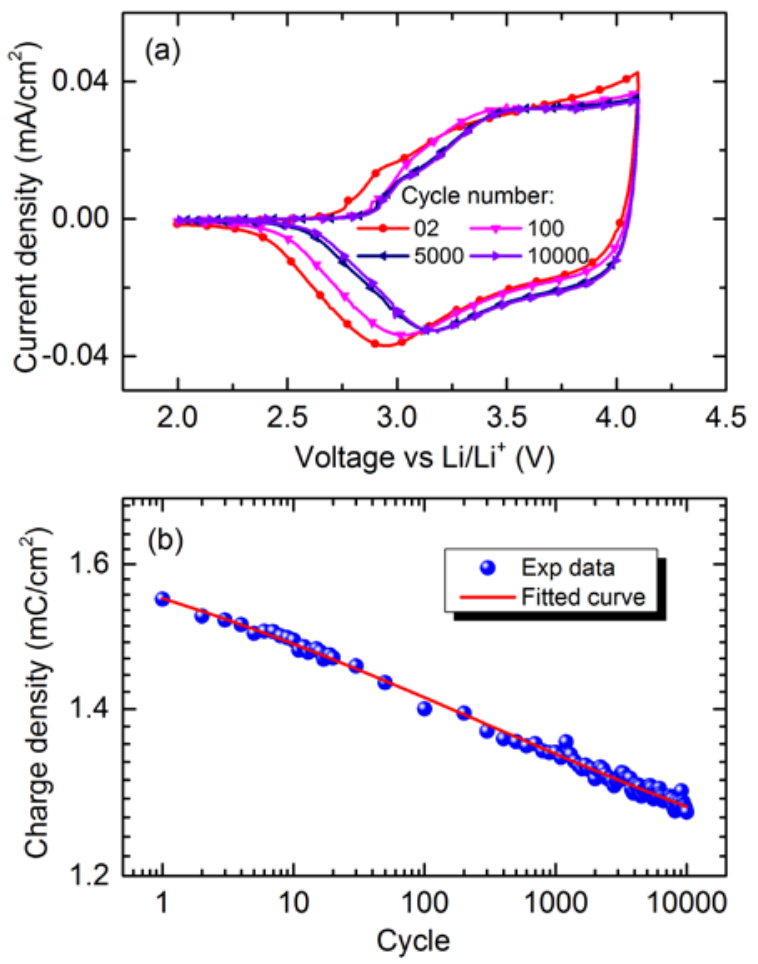

Fig. 5. Cyclic voltammograms (a) and associated charge density exchange (b) for a 285-nm-thick Nioxide-based film. Data in (a) were taken after the indicated number of cycles for voltage sweeps at 50 $\mathrm{mV} / \mathrm{s}$ at 2.0-4.1 V vs. $\mathrm{Li}^{+} / \mathrm{Li}$. In (b), the dots indicate experimental values and the curve was drawn as a fit to Eq. (1) with parameters $A_{1}=1.59, A_{2}=1.20, x_{0}=189$ and $p=0.36 \pm 0.02$. Partly from Wen et al. [14].

Eq (1) was found to apply to several Ni-oxide-based samples, studied in various voltage ranges, and hence seems to be of general validity [14]. The underlying reason for this kind of relationship is not obvious, however. We note that degradation and ageing phenomena often obey a "universal relaxation law" [48]. The specific case of dispersive chemical kinetics has been explored in a series of review papers by Plonka [49-53], which may give points of departure for elucidating Eq. (1). For a first-order kinetic rate equation (e.g., an unimolecular reaction or a bimolecular reaction with an excess of one reacting species), the time dependent concentration $c_{A}(t)$ is given by a stretched exponential function, i.e.,

$$
c_{A}(t)=c_{A}(0) \exp \left(-\left(\frac{t}{\tau}\right)^{\alpha}\right)
$$

where $\tau$ and $\alpha$ are constants. In the case of a second-order rate equation (e.g., a bimolecular reaction with equal concentration of reactants), this equation is replaced by

$$
c_{A}(t)=c_{A}(0) /\left(1+\left(\frac{t}{\tau}\right)^{\alpha}\right)
$$


which has formal resemblance to Eq. (1). Empirically, it may not be easy to clearly distinguish between fits to Eqs. (2) and (3), however, and more work is needed.

We finally note that the cycling durability can be enhanced by adding a small amount of Ir to Ni oxide [54]. In this case, the additive can make the charge density exchange as well as the optical modulation increase during extended CV cycling. Beneficial effects of other dopants have been studied too, and particularly interesting results have been reached with (Li,W) [55], (Li,Al) [56], (Li,Zr) [57] and LiPON [58].

\section{Conclusion}

We have outlined recent progress related to durability and materials rejuvenation for electrochromic devices containing films based on $\mathrm{W}$ oxide and $\mathrm{Ni}$ oxide. Adding $\mathrm{Ti}$ to $\mathrm{W}$ oxide, and Ir to Ni oxide, gave strongly improved properties. The charge density declination during extended voltammetric cycling could be reconciled with a power-law dependence, which may be related to dispersive chemical kinetics although the details are still unclear. Perhaps the finding with the most far-reaching consequences is that of galvanostatic rejuvenation of $\mathrm{W}$ oxide films, which we ascribe to ion de-trapping from deep sites.

We believe that improved device longevity is not only contingent on empirical studies of degradation in real time and under accelerated conditions but is critically dependent on the evolution of theory and modelling founded on basic physics and chemistry. Aspects of the work reported on above point in this direction.

\section{Acknowledgements}

Financial support was received from the European Research Council under the European Community's Seventh Framework Program (FP7/2007-2013)/ERC Grant Agreement No. 267234 (GRINDOOR). M.A.A. thanks the Mexican Council for Science and Technology (CONACyT) and the Centro de Ivestigación y de Estudios Avanzados (CINVESTAV-IPN) for financial support to work at Uppsala University.

\section{REFERENCES}

[1] UNEP, Buildings and Climate Change: Status, Challenges and Opportunities, United Nations Environmental Programme, Paris, France, 2007. 
[2] US Department of Energy, Washington, DC, USA; http://buildingsdatabook.eere.energy. gov/

[3] IPCC, Intergovernmental Panel on Climate Change; http://www.ipcc.ch.

[4] C.P. Kelley, S. Mohtadi, M.A. Cane, R. Seager, Y. Kushnir, Proc. Natl. Acad. Sci. 112 (2015) 3241-3246.

[5] B. Richter, D. Goldston, G. Crabtree, L. Glicksman, D. Goldstein, D. Greene, D. Kammen, M. Levine, M. Lubell, M. Savitz, D. Sperling, F. Schlachter, J. Scofield, J. Dawson, Rev. Mod. Phys. 80 (2008) S1-S107.

[6] G.B. Smith, C.G. Granqvist, Green Nanotechnology: Solutions for Sustainability and Energy in the Built Environment, CRC Press, Boca Raton, FL, USA, 2010.

[7] C.G. Granqvist, Crit. Rev. Solid State Mater. Sci. 16 (1990) 291-308.

[8] C.M. Lampert, C.G. Granqvist, editors, Large-Area Chromogenics: Materials and Devices for Transmittance Control, SPIE Institutes for Advanced Optical Technologies, Vol. IS 4, SPIE - The International Society for Optical Engineering, Bellingham, WA, USA, 1990.

[9] C.G. Granqvist, Nat. Mater. 5 (2006) 89-90.

[10] C.G. Granqvist, Sol. Energy Mater. Sol. Cells 99 (2012) 1-13.

[11] C.G. Granqvist, Thin Solid Films 564 (2014) 1-38.

[12] C.G. Granqvist, J. Vac. Sci. Technol. B 32 (2014) 060801/1-060801/13.

[13] M.A. Arvizu, C.A. Triana, B.I. Stefanov, C.G. Granqvist, G.A. Niklasson, Sol. Energy Mater. Sol. Cells 125 (2014) 184-189.

[14] R.-T. Wen, C.G. Granqvist, G.A. Niklasson, Appl. Phys. Lett. 105 (2014) 163502/1-63502/4.

[15] R.-T. Wen, C.G. Granqvist, G.A. Niklasson, "Eliminating degradation and uncovering iontrapping dynamics in electrochromic $\mathrm{WO}_{3}$ thin films", Nat. Mater., to be published (2015).

[16] C.G. Granqvist, Handbook of Inorganic Electrochromic Materials, Elsevier, Amsterdam, The Netherlands, 1995.

[17] C.G. Granqvist, Sol. Energy Mater. Sol. Cells 60 (2000) 201-262.

[18] İ. Bayrak Pehlivan, R. Marsal, E. Pehlivan, E.L. Runnerstrom, D.J. Milliron, C.G. Granqvist, and G.A. Niklasson, Sol. Energy Mater. Sol. Cells 126 (2014) 241-247.

[19] G.A. Niklasson, C.G. Granqvist, J. Mater. Chem. 17 (2007) 127-156.

[20] R.-T. Wen, C.G. Granqvist, G.A. Niklasson, Adv. Funct. Mater. 25 (2015) 3359-3370.

[21] H.J. Gläser, Large Area Glass Coating, von Ardenne Anlagentechnik, Dresden, Germany, 2000.

[22] A. Azens, G. Gustavsson, R. Karmhag, C.G. Granqvist, Solid State Ionics 165 (2003) 1-5.

[23] A. Azens, E. Avendaño, J. Backholm, L. Berggren, G. Gustavsson, R. Karmhag, G.A. Niklasson, A. Roos, C.G. Granqvist, Mater. Sci. Engr. B 119 (2005) 214-223. 
[24] C.A. Bishop, Vacuum Deposition onto Webs, Films and Foils, $2^{\text {nd }}$ ed., William Andrew, Waltham, MA, USA, 2011.

[25] A.W. Czanderna, D.K. Benson, G.J. Jorgensen, J.-G. Zhang, C.E. Tracy, S.K. Deb, Sol. Energy Mater. Sol. Cells 56 (1999) 419-436.

[26] C.M. Lampert, A. Agrawal, C. Baertlien, J. Nagai, Sol. Energy Mater. Sol. Cells 56 (1999) 449463.

[27] J. Nagai, G.D. McMeeking, Y. Saitoh, Sol. Energy Mater. Sol. Cells 56 (1999) 309-319.

[28] N. Sbar, M. Badding, R. Budziak, K. Cortez, L. Laby, L. Michalski, T. Ngo, S. Schulz, K. Urbanik, Sol. Energy Mater. Sol. Cells 56 (1999) 321-341.

[29] T. Kubo, J. Tanimoto, M. Minami, T. Toya, Y. Nishikitani, H. Watanabe, Solid State Ionics 165 (2003) 97-104.

[30] S.K. Deb, Philos. Mag. 27 (1973) 801-822.

[31] J.-P. Randin, J. Electr. Mater. 7 (1978) 47-63.

[32] B.W. Faughnan, R.S. Crandall, in Display Devices, edited by J.I. Pankove, Springer, Berlin Heidelberg, Germany, 1980; Topics in Applied Physics 40, pp. 181- 211.

[33] T.J. Knowles, Appl. Phys. Lett. 31 (1977) 817-818.

[34] C.G. Granqvist, S. Green, E.K. Jonson, R. Marsal, G.A. Niklasson, A. Roos, Z. Topalian, A. Azens, P. Georén, G. Gustavsson, R. Karmhag, J. Smulko, L.B. Kish, Thin Solid Films 516 (2008) 5921-5926.

[35] Y. Zhang, S.-H. Lee, A. Mascarenhas, S.K. Deb, Appl. Phys. Lett. 93 (2008) 203508/1-203508/2.

[36] S. Hashimoto, H. Matsuoka, J. Electrochem. Soc. 138 (1991) 2403-2408.

[37] S. Hashimoto, H. Matsuoka, Surf. Interface Anal. 19 (1992) 464-468.

[38] J. Göttsche, A. Hinch, V. Wittwer, Sol. Energy Mater. Sol. Cells 31 (1993) 415-428.

[39] F. Lin, J. Cheng, C. Engtrakul, A.C. Dillon, D. Nordlund, R.G. Moore, T.-C. Weng, S.K.R. Williams, R.M. Richards, J. Mater. Chem. 22 (2012) 16817-16823.

[40] F.S. Manchiu, Y. Yun, W.G. Durrer, J. Howard, U. Schmidt, C.V. Ramana, J. Mater. Sci. 47 (2012) 6593-6600.

[41] C.V. Ramana, G. Baghmar, E.J. Rubio, M.J. Hernandez, ACS Appl. Mater. Interfaces 5 (2013) 4659-4666.

[42] N.M. Vuong, D. Kim, H. Kim, J. Mater. Chem. C 1 (2013) 3399-3407.

[43] J. Bisquert, Electrochim. Acta 47 (2002) 2435-2449.

[44] J. Bisquert, V.S. Vikhrenko, Electrochim. Acta 47 (2002) 3977-3988.

[45] J. Bisquert, Phys. Rev. Lett. 91 (2003) 010602/1-010602/4.

[46] J. Bisquert, Phys. Rev. B 77 (2008) 235203/1-235203/15. 
[47] L. Berggren, J.C. Jonsson, G.A. Niklasson, J. Appl. Phys. 102 (2007) 083538/1-083538/7.

[48] A.K. Jonscher, Universal Relaxation Law, Chelsea Dielectrics Press, London, UK, 1996.

[49] A. Plonka, Annu. Rep. Prog. Chem., Sec. C: Phys. Chem 85 (1988) 47-75.

[50] A. Plonka, Annu. Rep. Prog. Chem., Sec. C: Phys. Chem 89 (1992) 37-88.

[51] A. Plonka, Annu. Rep. Prog. Chem., Sec. C: Phys. Chem 91 (1994) 107-174.

[52] A. Plonka, Annu. Rep. Prog. Chem., Sec. C: Phys. Chem 94 (1998) 89-175.

[53] A. Plonka, Annu. Rep. Prog. Chem., Sec. C: Phys. Chem 97 (2001) 91-147.

[54] R.-T. Wen, C.G. Granqvist, G.A. Niklasson, ACS Appl. Mater. Interfaces 7, 9319-9322 (2015).

[55] F. Lin, D. Nordlund, T.-C. Weng, R.G. Moore, D.T. Gillaspie, A.C. Dillon, R.M. Richards, C. Engtrakul, ACS Appl. Mater. Interfaces 5 (2013) 301-309.

[56] D. Gillaspie, A. Norman, C.E. Tracy, J.R. Pitts, S.-H. Lee, A. Dillon, J. Electrochem. Soc. 157 (2010) H328-H331.

[57] F. Lin, D. Nordlund, T.-C. Weng, D. Sokaras, K.M. Jones, R.B. Reed, D.T. Gillaspie, D.G.J. Weir, R.G. Moore, A.C. Dillon, R.M. Richards, C. Engtrakul, ACS Appl. Mater. Interfaces 5 (2013) 3643-3649.

[58] I.Y. Cha, S.H. Pask, J.W. Lim, S.J. Joo, Y.-E. Sung, Sol. Energy Mater. Sol. Cells 108 (2013) 2226. 